\title{
Suspension of Judgment, Rationality's Competition, and the Reach of the Epistemic ${ }^{*}+$
}

\author{
Errol Lord \\ University of Pennsylvania \\ forthcoming in The Ethics of Believing and Beyond, Routledge
}

\section{Introduction}

One of the most entrenched commitments in all of philosophy is the idea that, at least for some reactions, rationality should be understood in competitive terms. To understand rationality in this way is to think that there are multiple reactions competing against each other to win rationality's prize, which is having the status of being rational.

Traditional epistemology has eagerly embraced this competitive conception of rationality. But the participants in the competition have traditionally been seen as a small group. Belief and disbelief are obvious competitors. ${ }^{1}$ Nearly everyone, at least after some badgering, also

\footnotetext{
${ }^{*}$ Thanks to audiences at the Northeast Normativity Workshop, the Penn Normative Philosophy Group, and a Colloquium at Penn, especially Kate Nolfi, Nate Sharadin, Jennifer Morton, Sarah Paul, Daniel Fogal, Max Hayward, Jack Woods, Derek Shiller, Max Lewis, Grace Boey, Michael Vazquez, Paul Musso, Michael Weisberg. Thanks also to Jane Friedman, Jim Pryor, and Kurt Sylvan for crucial conversations and Sebastian Schmidt for very helpful written comments. The research leading to these results has received funding from the People Programme (Marie Curie Actions) of the European Union's Seventh Framework Programme (FP7/2007-2013) under REA grant agreement $n^{\circ}$ [609305]. Research on this project was also supported by the Freiburg Institute for Advanced Study (FRIAS), University of Freiburg, Germany.

${ }^{\dagger}$ Draft of September 20, 2019. Citing and quoting encouraged, but please ask permission before quoting (errol.lord@gmail.com).

${ }^{1}$ The orthodox assumption is that belief and disbelief are fundamentally the same attitude that are differentiated by a difference in content. When it comes to some proposition $p$, belief involves being settled that $p$ and disbelief involves being settled that $\neg p$. It is fine for us to assume this view, here. I hasten to note, though, that there is some motivation for thinking that while both involve settling, they are not essentially the same attitude. The basic idea is that belief involves a sort of positive settling, whereas disbelief involves a sort of negative settling. One motivation for going in for this is that you eliminate the requirement that one be competent with negation in order to disbelieve. On this view, disbelief is a relation to $p$, not $\neg p$.
} 
Suspension of Judgment, Rationality's Competition, and the Reach of the Epistemic

admits that there is a third participant, which is suspending judgment about whether $p$. When we suspend judgment, we adopt a sort of principled neutrality with respect to $p$ and $\neg p$.

On a flatfooted understanding of epistemic rationality's (coarse grained) competition, for any proposition $p$, the merits of believing $p$, disbelieving $p$, and suspending about $p$ compete against one another. When this competition is won by an option, that option is rational. Many think something even stronger, which is that there will always only be one winner; this is to say that for every proposition $p$ and every agent in some particular rational circumstance, only one of the options will win and thus be rational. While I think this is plausible, I won't assume it in full generality here. I will, however, assume that most of the time only one option will win. ${ }^{2}$

This paper has three main tasks. The first two tasks aim to complicate this traditional picture. The first complicating factor is that there are many different reactions one can have about $p$ that intuitively count as a sort of neutrality about $p$. Given this, it is not clear why we should think that there are only three participants in epistemic rationality's competition. This first complicating factor puts the onus on everyone to sort through these different ways of being neutral and take a stand on which ones compete with belief and disbelief.

The second complicating factor-discussion of which comprises the second part of the paper-is that there are really four participants in epistemic rationality's competition. This is fewer than all the ways that one can be neutral but more than the traditional three. I will argue that we should admit two sorts of suspension but shouldn't allow several other ways of being neutral. The arguments for this conclusion will turn on a conception of what it takes to be a participant in the relevant competition.

The final task is to argue that investigating the participants in rationality's competition is a good way of investigating the reach of epistemic rationality. This is important for several reasons. First, it gives us some leverage on just what the epistemic domain is. Second, and more specifically, it gives us leverage in the debate about whether only the evidence bears on epistemic rationality. A common thought shared by evidentialists - those that think only the evidence matters - is that evidentialism is strongly motivated because it doesn't make sense to have non-evidential factors bear on epistemic rationality; the common rationale given for this claim is that the epistemic is only concerned with the truth. In the third part of the paper, I will argue that this motivation is illusory. This is because the two sorts of suspension that are participants in epistemic rationality's competition can be justified by non-evidential factors. But they are in the epistemic's reach. So it is just not true that we can only appeal to the evidence when discussing the epistemic.

\footnotetext{
${ }^{2}$ Those who think that only one option will win hold the uniqueness thesis; those who think sometimes more than one option wins (or there are ties) are so-called permissivists. See Kopec \& Titelbaum (2016) for a primer.
} 


\section{On Being Neutral}

\subsection{Varieties of Neutrality}

Let's start by thinking about some baseline features of suspension of judgment. The first feature is that suspension is a reaction. It follows that not taking a stand is insufficient for suspension. At least before thinking of this example, I had no view about the claim that Trump is President and Mannheim has an odd number of hairs within its limits. That does not mean that I suspended judgment about that claim. I just had no view. ${ }^{3}$

A second baseline feature is that suspension is rationally evaluable. It is the sort of thing that can be rational and irrational. This is obviously needed if it is going to be a participant in epistemic rationality's competition.

A third baseline feature is that suspension is the sort of reaction that you can have for reasons. When you find out that the probability of rain tomorrow is about the same as the probability of no rain tomorrow, you can suspend judgment about whether it will rain tomorrow for reasons; most naturally, your reason will be the fact that the evidence is balanced.

So far these are the features that all participants in the competition will have. Belief and disbelief share them, and I think it's very plausible that they are necessary for being in the competition. Thus, these three features don't differentiate suspension from belief and disbelief. What does the differentiation?

To help get a grip on this question, it is helpful to think about what I will call one's intellectual outlook. One's intellectual outlook is a reckoning of one's doxastic stance on the world. Epistemic rationality's competition takes place within one's intellectual outlook. Different competitors play different roles within the outlook. ${ }^{4}$

To start, consider the fact that belief and disbelief are both ways to determine whether $p$ within one's outlook. When you believe $p, p$ is determined within your outlook; functionally, this means that, other things equal, you will proceed as if you inhabit a $p$-world. Similarly, when you disbelieve $p, \neg p$ is determined within your outlook. When you disbelieve $p$, you move forward as if you are in a $\neg p$-world.

One difference between suspension and belief and disbelief is that suspension does not involve determining $p$ in either of these ways. To use a nice phrase from Sturgeon (2010), suspension is a committed neutrality. So, in trying to figure out which state or states suspension

\footnotetext{
${ }^{3}$ This isn't meant to suggest that suspension of judgment is always the conclusion of some bit of reasoning, or is always the result of deliberation, or is in some other way always the result of an occurrent bit of mental activity. We sometimes automatically suspend. The point is just that for some claims we have no view rather than suspend. Thanks to Sebastian Schmidt for discussion here.

${ }^{4}$ This is misleading in one crucial way: It implies that there is only one intellectual outlook. This, I think, is false. One's partial beliefs provide another intellectual outlook. There is, of course, great debate about the relationship between the intellectual outlook comprised of one's coarse grained attitudes (belief, disbelief, suspension) and one's credences. As we'll see, I don't think we can reduce suspension to credences. I don't think we can do it for belief, either. Thus, I think the two outlooks are constitutively separate, which is not to say there are no necessary connections between the two.
} 
is, we need to investigate the ways in which we can be committed to neutrality. We need to investigate the ways in which $p$ can be in your outlook in a neutral way.

As it happens, it looks like there are several states that can be reasonably described as commitments to neutrality about whether $p$. An obvious candidate is middling credence about $p .^{5}$ Take credence .5 in $p$. This meets the three minimal requirements for being a competitor. It is also seems to be a way of having a commitment to a sort of neutrality with respect to $p$. Plausibly, there are many credences near the middle that have the same features. Hence, having a middling credence in $p$ is a sort of neutral stance about $p$.

A second batch of states is a range of related beliefs you might have about your position with respect to $p$. There are many different beliefs you could have that could naturally be construed as commitments to neutrality. For example, you might believe that the evidence is balanced. You might believe that there is no evidence for $p$ or for $\neg p$. You might believe that both $p$ and $\neg p$ are unknowable. You might believe that you are neither in a position to know $p$ nor in a position to know $\neg p$. You might believe that it is neither rational to believe $p$ nor rational to believe $\neg p$. You might believe that neither $p$ nor $\neg p$ are provable. The contents of each of these beliefs are about ways in which the rational merits of belief and disbelief are relatively neutral. Given this, it is plausible to think that believing those contents is a way of taking a neutral stance.

A third possibility is more practical. Suppose you start investigating $p$ and find out that the case for $p$ and the case for $\neg p$ is neutral in one of the above ways. You might come to believe that you are neither in a position to know $p$ nor in a position to know $\neg p$. But, in an obvious way, this belief is not really a stand about whether $p$. This belief is about your epistemic situation. So it wouldn't be crazy to think that forming that belief isn't sufficient for suspension. One thing the belief might prompt, though, is an intention not to form a belief or a disbelief. ${ }^{6}$ This intention seems straightforwardly to be a commitment to be neutral about $p$.

These three options are perhaps the most obvious. There are two unobvious neutral states that have been important to recent theorizing about suspension. The first is what Jane Friedman calls interrogative attitudes. ${ }^{7}$ These are attitudes that take as their object the question whether $p$. So, for example, when you are curious about whether $p$, you have an attitude directed at whether $p$. One of the main functional roles of this attitude is to dispose one to be on the look out for information that would settle whether $p$. Often we are in a state like this when we suspend. So, for example, when I'm deliberating about whether to teach at $10 \mathrm{am}$ or at noon and I find out that I lack some information about my train's future schedule, it might be rationally required for me to suspend about which time to teach. But I will keep the issue

\footnotetext{
${ }^{5}$ Sturgeon (2010) argues persuasively that middling credence actually isn't neutral in the right way. He thinks a degreed notion - what he calls thick confidence-is neutral in the right way. See $\mathrm{n}$. $\mathrm{x}$ below for more.

${ }^{6}$ Does this require doxastic volunteerism in order for the intention to be effective? It does require that we can execute intentions not to believe. This doesn't imply the strongest version of volunteerism, which maintains that we can execute intentions to believe.

${ }^{7}$ See Friedman (2013b,a, 2015).
} 
Suspension of Judgment, Rationality's Competition, and the Reach of the Epistemic

in my outlook. A natural way of spelling this out is in terms of adopting a questioning attitude about whether to teach at 10 or 12 -this state disposes me to do things that will put me in a position to settle the relevant question. Interrogative attitudes are states like this.

Interrogative attitudes are neutral positions about whether $p$. But they also involve a kind of openness towards answering whether $p$. In fact, at least paradigmatically, they dispose one to answer whether $p$. In other words, not only are they attitudes one takes towards the question of whether $p$, they are also attitudes that orient one towards answering whether $p$.

In contrast, it looks like there are attitudes one can take towards the question whether $p$ that are not attitudes that orient you towards answering whether $p$. So, consider the question of whether there was an even number of food particles in Karl Marx's beard at the time of his death. It is very likely that there is no evidence whatsoever that speaks to this question. So neither belief nor disbelief is appropriate. Simply forgetting about it is an option that might be permitted. But there seems to be a stance you could take that is more aggressive than this. Rather than merely dropping the issue, you can bury the issue, which is to say you can adopt an attitude towards whether $p$ that disposes you to ignore the question. This attitude makes you insensitive to information relevant to the question.

I'll call attitudes that are directed towards questions that bury those questions anti-interrogative attitudes. So while adopting an interrogative attitude keeps $p$ in your outlook in a way that orients you towards settling the question, adopting an anti-interrogative attitude puts whether $p$ in the outlook by, in effect, taking whether $p$ to be a bad question. In some cases this seems to be the right stance to take-e.g., when our epistemic situations look to be permanently impoverished when it comes to some question (later I'll argue there are some other situations where it makes sense to adopt these attitudes).

\subsection{Which Ones Participate?}

All of the stances just canvassed can be naturally seen as neutral stances towards $p$. Orthodoxy maintains that there is one neutral stance that is a participant in epistemic rationality's competition. Given the varieties of neutrality, someone who maintains this view needs to tell us which neutral state is the participant in the competition. Alternatively, one can give up the traditional view and allow for multiple neutral participants.

The first thing to say is that it is unclear what the rules of the game are here. What we need is a method for testing whether or not a stance is a participant in our competition. There are two simple and tempting tests to see if there is competition between our neutral states and belief and disbelief. The first test examines whether there is a rational tension between a particular neutral state and belief and disbelief. If there is a rational tension between adopting a neutral state and adopting belief or disbelief, then we have some evidence that those states compete. Call this the Tension Test.

The second test examines whether suspension is intuitively rational even when some candidate neutral state is not rational or whether suspension is intuitively irrational when some candidate neutral state is rational. If there is either mismatch, then that is evidence that the 
Suspension of Judgment, Rationality's Competition, and the Reach of the Epistemic

candidate state is not a participant in the competition. Call this the Rational Incongruity Test. ${ }^{8}$

As we'll see in a moment, I think we can use the Tension Test to rule out one of the options. However, it should be said right away that I don't think this test can rule out all of them. This is because I think it produces false positives. To put some of my cards on the table: Middling credences and beliefs about one's epistemic position with respect to $p$ will be in tension with believing $p$ or disbelieving $p$. However, I don't think this shows that those states are true participants in the competition. This is why we need the Rational Incongruity test. Before explaining why, let me first argue against the intention view.

\subsubsection{Against the Intention View}

Let's start with the intention view. That view maintains that to suspend is to form an intention to not believe or disbelieve $p$. I think there are clear cases where this view fails the Tension Test. This is because most of our reasons for intention are straightforwardly practical and thus can be generated no matter one's evidential situation. For example, imagine you are a scientist working for big tobacco in the early 1990s. You have been exposed to the overwhelming evidence that smoking cigarettes causes a variety of serious health problems. However, you are also now in a tough legal position because the federal government is poised to punish your company and perhaps even you for decades of deception. Your lawyer informs you that once all the evidence comes out, it will not be credible for you say that you didn't believe smoking kills. It would be better, he says, if you didn't believe one way or the other, especially if this neutrality can be supported by something that looks like sophisticated scientific reasoning.

In this case, I think it is very plausible that the scientist has decisive reasons to intend not to believe either that smoking kills or that it's not the case that it kills. He has decisive reason to intend to have no stand. This is because this would be the best thing for him practically. If he could get himself in that state, then he'd be able to truthfully testify that he is neutral (of course the explanation that he would give for that is not the true explanation). Nevertheless, this does not change the normative impact of the evidence. The scientist's legal trouble does not compete with the evidence. The evidence still demands belief. So it doesn't look like the reasons for intention compete with the reasons for belief in the needed way. Because of this, I think it's plausible that he both has decisive reasons to believe that smoking kills and decisive reason to intend to neither believe nor disbelieve.

Now, fortunately for the lovers of justice, it is also plausible that his beliefs are not under intentional control in the right way for his intention to have neither state to be causally efficacious. So while he has decisive reason to form that intention, he is unlikely to succeed in

\footnotetext{
${ }^{8}$ Just to be clear from the outset: I do not think that failing this test is always a decisive blow against a view. After all, if there are multiple ways of suspending judgment, then you are bound to have cases where one way is rational even though suspension in another way is not rational. Since my view posits two different ways of suspending, each way of suspending, on my view, will fail this test in some cases. That said, I will only use this test against theories that maintain there is only one sort of suspension-i.e., maintain that taking a particular neutral stance is necessary for suspension. The test is easier to wield against these theories.
} 
Suspension of Judgment, Rationality's Competition, and the Reach of the Epistemic

carrying out the intention. So perjury about his epistemic life is likely his only real option.

A similar objection can be leveled at a recent view defended by Masny (FC) for a view that is a hybrid of an intention view and belief view. According to Masny, suspension has three conditions that are all necessary and jointly sufficient: (i) $S$ believes that she neither believes nor disbelieves that $p$, (ii) $\mathrm{S}$ neither believes nor disbelieves that $p$, (iii) $\mathrm{S}$ intends to judge that $p$ or not- $p$.

The problem with this view is that it distorts the rational profile of suspension. Since this is the section about intention views, we can start there. Masny's intention condition doesn't pass either of our tests. First, it fails the Tension Test. It is easy to think of cases where one has very good reasons to intend to come to some judgment about whether $p$ that will not be reasons to suspend. For example, there are very good reasons for me to intend to judge that I was just offered a lifetime yearly income of $\$ 1 \mathrm{bn}$ (and, thus, I assume, good reasons to intend to judge that I was just offered a lifetime yearly income of $\$ 1 \mathrm{bn}$ or it is not the case that I was just offered a lifetime yearly income of $\$ 1 \mathrm{bn}$ ). But these don't seem to be reasons to suspend judgment about whether I was just offered a yearly income of $\$ 1 \mathrm{bn}$. What this shows is that Masny's intention condition does not pass the Tension Test—-there is no tension between that intention and belief and disbelief.

Masny's intention condition also fails the Rational Incongruity test. There are cases where it is irrational to have Masny's intention even though suspension is rational. It is not rational for me to intend to have an opinion about whether there was an even number of food particles in Marx's beard when he died, but it might be rational for me to suspend about this. After all, no evidence will ever settle this matter for me. This is reason to suspend; in fact, this sort of reason to suspend takes center stage in many discussions of the epistemology of suspension. ${ }^{9}$

Now, this might be unfair to Masny's considered view. After all, there are three conditions. Two of them involve mental states. So perhaps reasons to suspend on Masny's view will be some combination of reasons to have the belief that I don't believe $p$ or $\neg p$ and reasons to intend to judge that $p$ or judge that $\neg p$. In the yearly income case, I have excellent reason to believe that I disbelieve that I was just offered a yearly income of $\$ 1 \mathrm{bn}$; so I don't have strong reasons to believe I don't believe or disbelieve and intend to believe or disbelieve.

But there are cases where I have strong reasons to have both the belief and intention yet lack strong reasons to suspend. ${ }^{10}$ Suppose that Phillip thinks that he believes that members of a certain marginalized group are morally equal to Anglo-Saxons. But then psychologically observant friends start pointing out patterns of thought and action of his that provide evidence that he doesn't believe this. He responds by pointing to certain patterns of thought and action that provide evidence that he does believe they are equals. We can imagine that these two bodies of evidence are roughly on a par. Thus, he has good reason to suspend about whether

\footnotetext{
${ }^{9}$ See Rosenkranz (2007) for many of the details.

${ }^{10}$ This case is a counterexample to Russell (1997), Crawford (2004)'s belief views too, which is why I won't discuss them in the subsection about belief views.
} 
Suspension of Judgment, Rationality's Competition, and the Reach of the Epistemic

he believes the groups are equal-i.e., good reasons to believe that it is not the case that (he believes they are equal or he disbelieves they are equal). Further, we can imagine that Phillip is an ordinary person in contemporary society who thus has good reason to intend to have an opinion on this matter.

Thus, Phillip has strong reasons to believe he neither believes nor disbelieves and has strong reasons to intend to believe or disbelieve. He doesn't thereby have strong reasons to suspend. We can suppose that he has particularly good evidence for thinking the groups are equal; evidence that is even good enough to put him in a position to know that the groups are equal. This is compatible with him having good reasons to have the relevant belief and intention.

To be clear, I am not saying that Phillip is rational. It is plausible that he ought to believe they are equal. So there is a rational tension between the reasons for Masny's belief and intention and the reasons that bear on whether the groups are equal. So it looks like Masny's view passes the Tension Test. But it doesn't pass the Rational Incongruity test. This is because this is a case where Masny's neutral state is rational even though suspension is not.

The first upshot of this subsection is that the prospects for pure intention views are dim because the relevant intentions are not in tension with belief and disbelief in the right way; as we saw, things get better by moving from a pure intention view to a hybrid intention-belief view. But Masny's particular hybrid view also fails because it fails the Rational Incongruity test. Its intention-belief bundle can be rational even when suspension is not.

\subsubsection{Against The Credal View}

Now let's examine credences. The credal view of suspension maintains that to suspend about $p$ is to adopt some credence about $p$. Intuitively, it won't just be some single amount of confidence. Rather, there will be a range of credences one can adopt that are sufficient for suspension. We'll just say that suspension is middling credence. The Tension Test allows us to check this hypothesis. What we are looking for is a rational tension between middling credences and beliefs and disbeliefs.

Middling credences seem to pass the test. It is very plausible that having a middling credence about $p$ is in tension with belief or disbelief that $p$. This is because in order to rationally believe $p$, your credence in $p$ needs to be high enough, and it will never be high enough if one has a middling credence.

That's the good news for the credal view. The bad news is that it fails the Rational Incongruity Test. To pass this test, it would need to be that non-middling credence (which is non-suspension on this view) is in tension with suspension. This does not appear to be the case, as Friedman (FC) has demonstrated. ${ }^{11}$

\footnotetext{
${ }^{11}$ Sturgeon (2010) points out another reason to doubt suspension can be understood in terms of credence: Suspension is a committed neutrality, yet credences are extremely precise ways of not being neutral. This is evidence that credence is a particularly bad tool for understanding suspension.
} 
Suspension of Judgment, Rationality's Competition, and the Reach of the Epistemic

To see the problem, consider Lack of Evidence and Conjunction:

Lack of Evidence: If $A$ lacks evidence for $p$ and for $\neg p$, then it is permissible for $A$ to withhold about whether $p$.

Conjunction: If $A$ is permitted to withhold about $p, q, r \ldots n$, then $A$ is permitted to withhold about $(p \wedge q \wedge r \ldots \wedge n){ }^{12}$

Both of these principles are very plausible, but the credal view cannot vindicate them given the standard norms on credence. To see why, let's suppose any credence between .33 and .66 is middling. Now take three probabilistically independent claims $p, q$, and $r$. Suppose you lack evidence with respect to all three. Thus, from Lack of Evidence, it follows that you are permitted to suspend about all three. It should follow from Conjunction that you are permitted to suspend about their conjunction. But it doesn't follow from the credal view. This is because even if you had the absurdly high credence of .66 in all three of them, the standard norms on credence predict that your credence in their conjunction should be below .33 since your credence in the conjunction should be the product of your credences in the conjuncts. Thus, the credal view maintains that you are not permitted to suspend about their conjunction. That's false.

What's important for our test is that having non-middling credence is compatible with rational suspension. If suspension is middling credence, then when you are required to have a non-middling credence, you are required not to suspend. But in cases with the relevant form, you are permitted to both suspend about $(p \wedge q \wedge r)$ and have a non-middling credence about $(p \wedge q \wedge r)$. So having middling credence is not sufficient for suspension. Further, the reasons that bear on suspension are not always reasons that bear on whether or not to have middling credence. This is all evidence that middling credence is not a participant in the relevant competition.

\subsubsection{Against the Belief View}

Now let's turn to the most complicated case, which is the higher-order belief view. This view maintains that to suspend is to have some belief about your epistemic position with respect to $p$. To start, I will assume that the relevant belief is that you are neither in a position to know $p$ nor in a position to know $\neg p .^{13}$

Sturgeon understands suspension in terms of what he calls thick confidence (often known as mushy credence). Friedman (FC) points out, in effect, that this view fails the Rational Incongruity test too. This is because it predicts that suspension is always irrational when one ought to have a credence in some claim. This is false.

${ }^{12}$ This claim might be dubious in full generality. If you get enough conjuncts, perhaps one should disbelieve the conjunction whilst suspending about all the conjuncts. But it is very plausible when restricted to relatively small sets of claims. That is all I will need.

${ }^{13}$ This is the view Rosenkranz (2007) ends up adopting after considering several other potential contents. 
Suspension of Judgment, Rationality's Competition, and the Reach of the Epistemic

This view, like the credal view, passes the Tension Test. There is a tension between the relevant higher-order beliefs and believing $p$ and believing $\neg p$. That is, it is plausible that you are generally irrational to both believe or disbelieve $p$ and also believe that you are neither in a position to know $p$ nor in a position to know $\neg p$. Furthermore, it is plausible that reasons to believe that you are neither in a position to know $p$ nor in a position to know $\neg p$ compete with the reasons to believe $p$ and the reasons to believe $\neg p$. So the higher-order belief view seems to pass our first test.

As it was with the credal view, it is far from clear that having the relevant higher-order belief is necessary for suspension and thus it looks like the higher-order belief view fails the Rational Incongruity test. One reason why is that the higher-order belief requires conceptual sophistication out of reach of many agents who appear to be able to suspend. ${ }^{14}$ POsition TO KNOW is, at least seemingly, not an ordinary concept regularly possessed and deployed by ordinary people. But ordinary people regularly suspend judgment. So it seems unlikely that having that higher-order belief is necessary for suspension. The point is even sharper when it comes to immature humans and animals. It is even less plausible that they possess and regularly deploy those concepts. Yet they suspend.

Raleigh (FC) anticipates this overintellectualization objection. In response, he maintains that the content of the relevant belief is less sophisticated. Suspending, on Raleigh's view, involves "a belief or opinion that one cannot yet tell whether or not $p$, based on one's evidence." This is certainly better, but notice that this still requires one to have the capacity to have beliefs about evidence. Further, one needs to have the capacity to have beliefs about one's epistemic situation with respect to $p$ in order to suspend. This is a feature that it shares with all higher-order belief views. This is because all higher-order belief views require beliefs about one's own situation in order to suspend. Suspension, on these views, thus requires a lot more conceptual sophistication than belief and disbelief. To believe or disbelieve $p$, you just need to have the capacity to entertain $p$. To suspend, you need to entertain not only $p$, you also need to entertain claims about your intellectual situation vis-á-vis $p$. On Raleigh's view, you need to be able to entertain thoughts about what your evidence indicates.

Raleigh is clear eyed about the added sophistication his view requires. He thinks that it is an important truth that suspension requires more intellectual sophistication than belief. $\mathrm{He}$ writes, "it is not at all clear that we are prepared to ascribe the attitude of suspending judgement to simple believers such as young children or animals-I might describe my toddler or my dog as hesitant or uncertain or just ignorant whether $p$, but it would sound pretty strange to describe them as agnostic whether $p$. Agnosticism is plausibly a more sophisticated, intellectually demanding attitude than belief."

If Raleigh is talking about vanilla suspension - the competitor in our competition-then I think this is seriously mistaken. Young children and animals do suspend. Raleigh and I appear to agree that HOB views threaten this. His modus ponens is my modus tollens. To see why this is seriously mistaken, it helps to have a fleshed out alternative on the table. So I will

\footnotetext{
${ }^{14}$ Friedman (2013a) makes a similar point.
} 
Suspension of Judgment, Rationality's Competition, and the Reach of the Epistemic

postpone a full explanation of why I think it is wrong to deny young children and animals the capacity to suspend to the next subsection.

To warm up to the idea, though, note that it is not surprising for there to be problems for the higher-order belief view, given the way I've set things up. After all, what we are looking for are types of mental states that compete against each other. But higher-order beliefs are just beliefs. There is no clash in kind between beliefs and beliefs. So any clash here will simply be a clash in contents. There is a clash in contents here-hence passing the Tension Test. But a simple clash in contents shouldn't make for a new participant in the competition. After all, any content $q$ that is inconsistent with $p$ will clash with a belief that $p$. But that doesn't mean that beliefs that $q$ are participants in the relevant competition.

I thus think we should rule out intentions, middling credence and higher-order beliefs from the competition. While there are rational connections between credences about $p$, higherorder beliefs about one's rational situation vis-á-vis $p$, and belief and disbelief about $p$, we shouldn't think that those states all compete against each other.

\subsubsection{For Interrogative and Anti-Interrogative Attitudes}

This leaves interrogative attitudes and anti-interrogative attitudes. I do think that these two states are participants in our competition. In order to see why, let's return to the idea of an intellectual outlook. We already know two ways for $p$ to figure into one's outlook. One can believe that $p$ or disbelieve that $p$. When $p$ figures into one's outlook in either of these ways, the status of $p$ is both settled and determined. When you believe that $p, p$ is determined in your outlook in virtue of the fact that you take $p$ to be the case. When you disbelieve $p, p$ is determined in your outlook in virtue of the fact that you take $\neg p$ to be the case. To help contrast this with the sort of determination involved in anti-interrogative attitudes (to be spelled out more below), let's call this Worldly Determination-so-called because beliefs determine the status of $p$ by taking a stand about the world.

The fact that belief and disbelief worldly determine the status of $p$ within an outlook is explained by the functional roles of those states. Belief that $p$ disposes one to use $p$ flatout in reasoning. So, other things equal, when you believe $p$, you will move forward in your interactions with the world as if you inhabit a $p$-world.

When we think about things this way, it is easy to see the evidence for thinking that interrogative and anti-interrogative attitudes are participants in the competition. For it looks like their functional roles are in obvious tension with the functional role of belief. Both interrogative and anti-interrogative attitudes are essentially worldly undetermined states. When you adopt either sort of attitude about whether $p$, you enter a state that essentially lacks a disposition to use $p$ flat-out in reasoning. Further, interrogative attitudes also essentially dispose you to settle the question of whether $p$. So they dispose you to do things that will induce belief, but essentially lack the function of belief. Given this, it is easy to see why reasons to form interrogative attitudes compete against the reasons to believe.

We can say similar things about anti-interrogative attitudes. These attitudes also essen- 
tially lack the dispositions involved in worldly determination. Further, these attitudes dispose you to ignore any $p$-relevant information, at least as it pertains to $p$. So, unlike the interrogative attitudes, these attitudes seek to prevent you from determining whether $p$ via belief. They seek to prevent you from hearing the siren call of reasons to worldly determine whether $p$. Antiinterrogative attitudes thus provide a different way of determining $p$ 's status in your outlook. We can call it Agnostic Determination. Given the fact that anti-interrogative attitudes involve agnostic determination, one sort of sufficient reason to adopt an anti-interrogative attitude is information that strongly suggests both that the current information doesn't sufficiently confirm $p$ or $\neg p$ and that future information won't sufficiently confirm $p$ or $\neg p .^{15}$

Now we are in a position to see why it is plausible to think that these four attitudes are participants in our competition. It is because they are competing ways to settle the status of $p$ in your outlook. They are competing because their respective functional roles are in direct tension with each other. A belief that $p$ is in tension with a disbelief that $p$ because its functional role involves taking the world to be a $p$ world whereas the functional role of disbelief involves taking the world to be a $\neg p$ world; beliefs and disbeliefs are in tension with both interrogative attitudes and anti-interrogative attitudes because beliefs and disbeliefs are essentially worldly determining whereas interrogative and anti-interrogative attitudes are not; and interrogative attitudes are in tension with anti-interrogative attitudes because anti-interrogative attitudes are essentially agnostic determining whereas interrogative attitudes are essentially not. ${ }^{16}$

Before moving on, it is worth considering an objection to this core thought - the thought that the functional roles of the four states are in direct conflict. The objection contends that the functional roles of interrogative and anti-interrogative attitudes are not in fundamental tension with the functional roles of beliefs because one can rationally believe $p$ even though one is disposed to gather more $p$-related information or is disposed to ignore $p$-related information. If this is right, then it is not clear that my view passes the Rational Incongruity test. It looks like we can get cases where one rationally believes and rationally has an interrogative or antiinterrogative attitude.

I agree that there are cases where one rationally believes $p$ and is rationally disposed to gather more information (think of a surgeon who rationally believes she needs to take out your liver). I also agree that there are cases where one rationally believes $p$ and is rationally disposed to ignore $p$-related information (think of the pathological overchecker who has already made sure the oven is off 17 times). But this is not enough to show that there are cases where it is

\footnotetext{
${ }^{15}$ Anti-interrogative attitudes thus play the role that Rosenkranz (2007) wants agnosticism to do. He tries to do the work with higher-order beliefs, but fails for the reasons laid out above. Miracchi (FC) also discusses states with the functional role of anti-interrogative attitudes.

${ }^{16}$ Some virtue epistemologists-e.g., Sosa and Miracchi-have worried a great deal about how suspension can be accommodated in a virtue theoretic framework. The basic issue is how to explain the epistemology of suspension in terms of the sorts of epistemic aims central to such frameworks (e.g., the aim to know). This has led Miracchi to affirm that the epistemology of suspension is derivative in a certain way from the epistemology of belief. My framework makes this unnecessary. Miracchi's mistake, it seems to me, is to think that suspension is, at bottom, just a lack of belief (which is sometimes accommpanied by some other things). This is what makes it difficult to show that one can manifest aim at epistemic goods whilst suspending.
} 
Suspension of Judgment, Rationality's Competition, and the Reach of the Epistemic

rational to believe $p$ and rational to have interrogative or anti-interrogative attitudes. This is because there is more to interrogative and anti-interrogative attitudes than these interrogative or anti-interrogative dispositions. Remember, interrogative and anti-interrogative attitudes are essentially not worldly determining. That means they are partly individuated by a functional lack - the lack of dispositions to move around as if it is a $p$ or $\neg p$ world.

This, I admit, is a bit tricky to get one's mind around at this level of abstraction. It helps to contrast particular agents who are paradigms of believing and suspending. So, consider Beatrice, Ingrid, and Anjali:

Beatrice the Believer: Beatrice has just finished investigating whether smoking causes cancer. It clearly does, and she believes so. She is robustly disposed to treat the actual world as a smoking-causes-cancer world, including disposed to use that claim as a premise in reasoning and disposed to assert that claim.

Ingrid the Inquirer: Ingrid has become interested in whether evidentialism about epistemic rationality is true. She has read some journal articles on it and the results are mixed. She has a questioning attitude towards the question of whether evidentialism is true. This disposes her to seek out more information, see evidentialism relevant information as salient etc.

Anjali the Agnostic: Anjali is prompted by an obnoxious philosophy example to consider whether Karl Marx had an odd or even number of food particles in his beard at the time of his death. This is a ridiculous question to consider, and it is clear to Anjali that she will never be in a position to determine the answer. So she adopts an agnostic attitude towards the question, which disposes her to ignore both the question and any information relevant to answering it (unfortunately the obnoxious philosopher keeps bring it up, which makes it difficult to be fully agnostic!).

The key point about Ingrid and Anjali is that they don't merely have interrogative and antiinterrogative dispositions. Ingrid has interrogative dispositions in virtue of having a questioning attitude and Anjali has anti-interrogative dispositions in virtue of having an agnostic attitude. $^{17}$

This is of a piece with believing and disbelieving. One can have belief or disbelief dispositions even if one doesn't believe or disbelieve. When one does believe or disbelieve, one has those dispositions in virtue of believing or disbelieving. What this shows, at a minimum, is

\footnotetext{
${ }^{17}$ While it might appear otherwise, these claims are not incompatible with a purely dispositionalist view of doxastic attitudes. For on plausible dispositionalist views, whether one believes is determined by whether one has a sufficient amount of the relevant dispositions (with sufficient robustness). When one does believe, one might have any particular disposition in virtue of the fact that one believes, even if whether one believes is determined by having a sufficient number of dispositions of the right kind.
} 
that finding agents who rationally believe and rationally have questioning or agnostic dispositions is not enough to show that my view fails the Rational Incongruity test.

Our fleshed out intellectual outlook can provide an explanation of why it is that middling credence and certain higher-order beliefs stand in tension with belief and disbelief. It is because reasons to have the higher-order beliefs or middling credence provide reasons against belief and disbelief. Reasons to have middling credence about $p$ will be provided by the evidence, and facts about roughly equitable evidence for $p$ and $\neg p$ will themselves provide reasons to suspend in one of the two ways. Similarly, reasons to hold the higher-order beliefs will be evidence about the deficiency of one's epistemic position, and that evidence itself will provide reasons to suspend in one of our two ways. ${ }^{18}$

Finally, we are in a position to respond to Raleigh's challenge laid out above. Recall that Raleigh's higher-order belief view — like all higher-order belief views - maintains that suspension about $p$ is a matter of having beliefs about our epistemic position with respect to $p$. I objected above to the added sophistication this demands from suspenders. Raleigh embraces this result. He maintains that we hesitate from ascribing suspension to young children and animals. Further, he thinks that suspension only makes sense given certain intellectual sophistication.

I hope it is clear now that my picture casts serious doubt over these claims. This much seems right: There is a good design rationale for having interrogative and anti-interrogative attitudes. This is because it is important to be able to place $p$ in your outlook in ways that are not worldly determining. When it comes to interrogative attitudes, it is important to be able to place $p$ in your outlook in a way that aids determination of the truth-value of $p$. When it comes to anti-interrogative attitudes, it is important to be able to close $p$ from future investigation. It would be surprising if the only ways animals or small children could place $p$ in their outlooks is by believing or disbelieving-i.e., by taking a stance that involves worldly determination.

The upshot of this subsection is two-fold. First, there are good reasons for excluding intentions, credences, and higher-order beliefs. Intentions and higher-order beliefs don't have the right subject matter. The relevant intentions are about believing or disbelieving $p$, whereas the higher-order beliefs are about one's epistemic situation vis-á-vis $p$. Credences do have the right subject matter-viz., $p$ - but they don't seem to settle whether $p$ when it comes to the relevant outlook.

The second upshot is that there is a good case for including interrogative and anti-interrogative attitudes in epistemic rationality's competition. They are both about the right subject matter and they are ways of settling whether $p$ in the right outlook. If this is right, then orthodoxy is vindicated insofar as it was right to think that suspension is a full-blooded alternative to belief. But, at the same time, if this is right, then orthodoxy was wrong to think that there were only three participants in epistemic rationality's competition. There are four, including two different varieties of suspension that compete with each other as well as with belief and disbelief.

\footnotetext{
${ }^{18}$ For more details about this, see Lord \& Sylvan (FC).
} 


\section{The Reach of the Epistemic}

One of the central debates about epistemic rationality is about whether the evidence provides the only source of epistemic reasons. Evidentialists think that only the evidence can provide epistemic reasons. Pragmatists deny this and hold that sometimes non-evidential considerations provide epistemic reasons. ${ }^{19}$

Many-including past time slices of me - think that evidentialism has a sort of default status because the evidential is clearly within the reach of the epistemic, whereas it is mysterious how non-evidential factors can be within the reach of the epistemic. ${ }^{20}$ It's not entirely clear what this means, but the intuitive idea is that the epistemic is essentially tied to the truth, and thus in order for some consideration to bear on epistemic rationality, it has to have some connection to the truth. The evidence clearly has this connection; it's not clear how non-evidential considerations could fit.

I don't doubt the force of this thought when we are at the beginning of our inquiry. But the strategy for thinking about epistemic rationality deployed in this paper gives us the resources to more precisely investigate the ultimate force of this thought. By thinking about the participants of epistemic rationality's competition, we are thereby thinking about which sort of considerations bear on epistemic rationality - they are the considerations that recommend the reactions that are the participants.

The important point is this: If belief and disbelief were the only games in town, then evidentialism would be easily vindicated. But by nearly everyone's lights they are not. The competition also includes suspension. And the view about suspension defended in this paper has the resources to cause serious trouble for evidentialism. To see this, we need to think about the sorts of reasons one might have for forming interrogative and anti-interrogative attitudes. Some of them will be non-evidential.

Here is a pair of famous cases that illustrate this for interrogative attitudes: ${ }^{21}$

Low Bank: It is Friday afternoon and Sarah and Yvette have a paycheck to deposit. They drive by the bank on the way home. There is a long line stretching out the door. Sarah has good reason to think that the bank is open on Saturday - she was there on Saturday two weeks ago. There is no rush to deposit the check.

High Bank: It is Friday afternoon and Sarah and Yvette have a paycheck to deposit. They drive by the bank on the way home. There is a long line stretching out the door. Sarah has good reason to think that the bank is open on Saturday-she was there on Saturday two weeks ago. Unlike Low Bank, though, it is crucial for them to deposit the check before Monday. Their mortgage payment is due on Sunday and they don't have enough in the account to pay without the check being deposited.

\footnotetext{
${ }^{19}$ For a primer on this debate, see Lord (FC).

${ }^{20}$ See, e.g., Ichikawa et al. (2012), Gardiner (FC).

${ }^{21}$ These are slight variations on cases originally found in Stanley (2005). See Schroeder (2012, 2018), DeRose (2009), Fantl \& McGrath (2010).
} 
Suspension of Judgment, Rationality's Competition, and the Reach of the Epistemic

In High Bank, Sarah and Yvette have reasons to suspend that they lack in Low Bank. The fact that their mortgage depends on the deposit is itself a reason to form an interrogative attitude about whether the bank is open on Saturday. It is a reason to form an attitude about whether $p$ that disposes them to do things to settle whether $p$. And this reason is quite strong. This explains the common intuition that it is not rational for them to believe the bank is open on Saturday in High Bank. It's not rational because the reasons to suspend defeat the reasons to believe. They ought to suspend by forming an interrogative attitude about whether $p$.

Things are not so in Low Bank. There isn't that reason to form an interrogative attitude. So they don't have that reason to suspend competing with the reasons to believe. Thus, there isn't that reason to suspend defeating the reasons to believe-i.e., the evidence. This explains the widespread intuition that, in Low Bank, it is rational for them to believe the bank is open on Saturday.

Of course, the rub is that by stipulation the evidence is the same in both cases. So if there is a rational difference between the two cases, non-evidential factors can make a difference to epistemic rationality. This, I think, is the conclusion we should draw. The key to demystifying the anti-evidentialist intuitions is understanding the nature and rational profile of suspension.

Similar things can be said about anti-interrogative attitudes. Take the following pair of cases as an illustration: ${ }^{22}$

Gritty PhD Student: Jason is a struggling second year $\mathrm{PhD}$ student at a top $\mathrm{PhD}$ program. Jason is African American and is the first person in his family to go to university. While he excelled at his small liberal arts college, he is finding it difficult to make his place in graduate school. The faculty are busy and distant, and some of them are noticably nervous interacting with him. As he progresses through his second year, the evidence begins to mount that he will not succeed in the program. He has poured nearly all his efforts as an adult to get to this place, though, and it is entirely unclear what he should do if graduate school does not work out.

Trust Fund PhD Student: Shep is a struggling second $\mathrm{PhD}$ student at a top $\mathrm{PhD}$ program. He is a white male student who was a legacy undergraduate at Harvard. He became interested in philosophy and succeeded in it as an undergraduate despite a lack of true passion. He didn't know what to do after Harvard, so he applied to PhD programs on a whim. He got into several top programs and chose the one he did mainly for its proximity to good bars. As he progresses through his second year, the evidence begins to mount that he will not succeed in the program. This doesn't bother him too much because if he drops out he can always live off his trust fund.

We can stipulate that Jason and Shep's evidence about whether they will succeed is the same. And we can suppose that it is weighty. How should they react to it? Some have the intuition that it would, at the very least, be rational for Jason to display grit, which involves sticking to

\footnotetext{
${ }^{22}$ This case is inspired by Paul \& Morton (2018). See also Marušić (2015).
} 
Suspension of Judgment, Rationality's Competition, and the Reach of the Epistemic

one's long term plans despite significant evidence that one will not succeed. We can suppose, if it helps, that Jason's evidence is misleading. Once he pushes through his second year course work, he will find his research bearings, connect with a thoughtful and supportive advisor, and go on to have a successful career.

The view sketched in this paper can explain what is going on here. Certain non-evidential facts-e.g., the fact that a career in philosophy is what suits Jason the most, the fact that there are no good alternative plans for Jason - provide reasons for Jason to suspend judgment about whether he will succeed. They do this by providing reasons to form an anti-interrogative attitude. This attitude will dispose him to ignore (some of) the mounting evidence, which is what he needs to do in order to push through the second year bottleneck. Now, it should be said, that the dispositions involved in anti-interrogative attitudes can be more or less robust (or more or less wide-ranging). They might dispose him to ignore anecdotal evidence, but they won't dispose him to ignore evidence provided by a letter officially removing him from the program. That, though, is all to the good, for it does seem like anti-interrogative attitudes should come in degrees. Perhaps there are other cases where fully robust dispositions are what is called for.

Things might be different for Shep. Given his independent resources and lack of serious passion for philosophy, he lacks many of the reasons to suspend that Jason possesses. Given this, the only rational option for Shep might be to believe he will not succeed and seek out something else. If this is right, then non-evidential factors make a difference to epistemic rationality.

My point here is that the view of suspension defended in this paper makes perfectly good sense of why these non-evidential factors bear on epistemic rationality. It is because they bear on suspension, and suspension competes against belief and disbelief when it comes to epistemic rationality. So the account gives an independently motivated rationale for allowing some nonevidential factors to be within the epistemic's reach.

Now, of course, this does not settle the issue. Evidentialists will disagree with my verdict of the bank cases and the grit cases. The important point is that the view developed here gives us a new way to adjudicate the debate, and it is not clear why one would think that evidentialism is the default. The evidentialist can disagree that non-evidential facts provide reasons to form interrogative and anti-interrogative attitudes or they could disagree that interrogative and anti-interrogative attitudes are forms of suspension. In order to respond in either way they need to defend precise evidentialist-friendly views about which participants compete in the epistemic competition and precise views about the normative profile of those states. This is a much more challenging task than bunching up their noses in an incredulous stare at the thought that non-evidential considerations are within the epistemic's reach. In this way, at least, the framework developed here moves the debate about evidentialism forward. 
Suspension of Judgment, Rationality's Competition, and the Reach of the Epistemic

\section{References}

Crawford, S. (2004). A solution for russellians to a puzzle about belief. Analysis, 64(3), 223-29.

DeRose, K. (2009). The Case for Contextualism. Oxford University Press.

Fantl, J. \& McGrath, M. (2010). Knowledge in an Uncertain World. Oxford University Press.

Friedman, J. (2013a). Question-directed attitudes. Philosophical Perspectives, 27(1), 145-174.

Friedman, J. (2013b). Suspended judgment. Philosophical Studies, 162(2), 165-181.

Friedman, J. (2015). Why suspend judging? Noûs, 50(4).

Friedman, J. (FC). Rational agnosticism and degrees of belief. In T. Gendler \& J. Hawthorne (Eds.), Oxford Studies in Epistemology, volume 4. Oxford University Press.

Gardiner, G. (FC). Evidentialism and moral encroachment. In K. McCain (Ed.), Believing in Accordance with the Evidence: New Essays on Evidentialism. Springer.

Ichikawa, J., Jarvis, B., \& Rubin, K. (2012). Pragmatic encroachment and belief-desire psychology. Analytic Philosophy, 53(4), 327-343.

Kopec, M. \& Titelbaum, M. (2016). The uniqueness thesis. Philosophy Compass, 11(4), 189-200.

Lord, E. (FC). Evidence and epistemic reasons. In M. Lasonen-Aarnio \& C. Littlejohn (Eds.), The Routledge Handbook of Evidence. Routledge.

Lord, E. \& Sylvan, K. (FC). Reasons to withhold, higher-order evidence, and defeat. In J. Brown \& M. Simion (Eds.), Reasons, Justification, and Defeat. Oxford University Press.

Marušić, B. (2015). Evidence and Agency: Norms of Belieffor Promising and Resolving. Oxford University Press.

Masny, M. (FC). Friedman on suspended judgment. Synthese, (pp. 1-18).

Miracchi, L. (FC). When evidence isn't enough: Suspension, evidentialism, and knowledge-first virtue epistemology. Episteme.

Paul, S. \& Morton, J. (2018). Grit. Ethics, 129(2), 175-203.

Raleigh, T. (FC). Suspending is believing. Synthese.

Rosenkranz, S. (2007). Agnosticism as a third stance. Mind, 116(461), 55-104.

Russell, B. (1997). What is an agnostic. The Basic Writings of Bertrand Russell, 2.

Schroeder, M. (2012). Stakes, withholding, and pragmatic encroachment on knowledge. Philosophical Studies, $160(2), 165-185$.

Schroeder, M. (2018). Rational stability under pragmatic encroachment. Episteme, 15(3), 297-312.

Stanley, J. (2005). Knowledge and Practical Interests. Oxford University Press.

Sturgeon, S. (2010). Confidence and coarse-grained attitudes. In T. S. Gendler \& J. Hawthorne (Eds.), Oxford Studies in Epistemology (pp. 3-126). Oxford University Press. 